\title{
KECAKAPAN HIDUP TERKAIT KESEHATAN REPRODUKSI PADA SISWA SMA YANG MENGIKUTI PROGRAM PIK-R DI KABUPATEN TABANAN
}

\author{
Rini Winangsih", ${ }^{1,2}$, Kadek Sri Ariyanti, ${ }^{1,2}$, Dewa Ayu Ari Kusumayuni, \\ ${ }^{1}$ Program Studi DIII Kebidanan, ${ }^{2}$ STIKES Advaita Medika Tabanan \\ Korespondesi penulis: renarafae112@gmail.com
}

\begin{abstract}
Abstrak
Latar Belakang: Periode remaja merupakan periode yang kritis dimana terjadi pertumbuhan fisik, psikologis dan intelektual yang sangat pesat, sehingga sangat rawan terjerumus pada perilaku berisiko. Perilaku berisiko remaja di Indonesia antara lain penggunaan narkoba dan alkohol, serta hubungan seks pranikah yang dapat meningkatkan jumlah kasus infeksi HIV/AIDS. Untuk menanggapi permasalahan kesehatan reproduksi remaja, pemerintah telah mencanangkan Program PIK-R. Tujuannya untuk memberikan pelayanan informasi dan konseling kesehatan reproduksi, pendewasaan usia perkawinan, kecakapan hidup, gender serta kemampuan advokasi dan KIE. Pendidikan kecakapan hidup bagi remaja sangat penting untuk mendukung perkembangan individu agar menjadi orang dewasa yang bertanggungjawab. Untuk menjalani hidup yang teratur, individu memerlukan keterampilan-keterampilan yang dibutuhkan masyarakat untuk melakukan sesuatu secara teratur.
\end{abstract}

Metode: Penelitian ini menggunakan rancangan cross sectional. Responden dalam penelitian ini adalah 150 orang siswa yang mengikuti Program PIK-R yang berasal dari tiga SMA di Kabupaten Tabanan. Sampel diambil dengan cara purposive sampling. Pengumpulan data dilakukan dengan cara survey menggunakan kuesioner.

Hasil: Penelitian menunjukkan bahwa Kecakapan hidup terkait kesehatan reproduksi pada siswa SMA yang mengikuti Program PIK-R sebagian besar dalam kategori baik, yaitu sebanyak 116 orang $(77,33 \%)$.

Simpulan: Program PIK-R memberikan dampak yang positif terhadap kecakapan hidup remaja terkait kesehatan reproduksi.

Kata Kunci: Kecakapan Hidup, Kesehatan Reproduksi Remaja, PIK-R

\section{Pendahuluan}

Masa remaja menurut WHO merupakan tahap transisi dari masa kanak-kanak ke dewasa, dengan batasan usia 12 sampai dengan 24 tahun. Sedangkan menurut Menteri Kesehatan RI tahun 2010, batasan usia remaja adalah 10 sampai dengan 19 tahun. Berdasarkan Undang-Undang Hukum Perdata (Pasal 330 ayat 1), mereka yang belum genap berusia 21 tahun dinyatakan belum dewasa. Pada periode ini, terjadi pertumbuhan fisik, psikologis dan intelektual yang sangat pesat. Sifat khas remaja adalah memiliki rasa ingin tahu yang sangat tinggi. Mereka lebih berani mengambil risiko atas perbuatannya tanpa mempertimbangkan secara matang. Jika remaja mengambil keputusan yang tidak tepat, maka remaja akan terjerumus dalam perilaku berisiko (Gunarsa, 2008).

Perilaku berisiko remaja di Indonesia menurut penelitian Lestary dan Sugiharti (2007) adalah penggunaan narkoba dan alkohol, serta hubungan seks pranikah. Perilaku seks tersebut menunjukkan hubungan yang signifikan dengan pengetahuan, sikap, pendidikan seks, akses terhadap media informasi serta lingkungan, seperti orang tua dan perilaku teman sebaya yang berisiko. 
Persentase seks pranikah pada remaja di Indonesia cukup tinggi, yaitu $4,5 \%$ pada lakilaki usia 15-19 tahun dan 14,6\% pada usia 20-24 tahun. Sedangkan pada remaja perempuan usia 15-19 tahun sekitar $0,7 \%$ dan $1,8 \%$ pada usia $20-24$ tahun. Alasan tertinggi remaja melakukan seks pranikah adalah penasaran/ingin tahu (57,5\% pria). Pada usiausia tersebut remaja belum memiliki keterampilan hidup dan masih labil (Infodatin, 2012). Seks pranikah akan menyebabkan kehamilan yang tidak diinginkan (KTD) terutama pada remaja. Berdasarkan Riset Kesehatan Dasar (Riskesdas) 2013, masih didapatkan kehamilan di usia sangat muda yaitu kurang dari 15 tahun, meskipun dengan proporsi yang sangat kecil $(0,02 \%)$. Sedangkan proporsi kehamilan di usia 15-19 tahun adalah $1,97 \%$, terutama di pedesaan.

Kehamilan pada remaja akan berujung pada pernikahan usia muda. Menurut (UNDESA, 2010), Indonesia merupakan negara dengan persentase tertinggi pernikahan usia muda dengan peringkat ke37 di dunia, serta peringkat kedua di Asia Tenggara setelah Kamboja. Pada tahun 2010, 158 negara melegalkan usia menikah yaitu 18 tahun ke atas. Sedangkan di Indonesia, Undang-Undang Perkawinan mengizinkan pria yang berusia 19 tahun dan wanita berusia 16 tahun untuk melakukan pernikahan. Sebanyak 0,2\% atau lebih dari 22.000 wanita usia 10-14 tahun di Indonesia sudah berstatus menikah. Pernikahan usia muda sangat berisiko karena masih kurangnya kesiapan dari aspek kesehatan, mental, emosional, pendidikan, sosial ekonomi dan kesehatan reproduksi. Pernikahan usia muda menggambarkan kualitas penduduk yang rendah dan menjadi fenomena di masyarakat (BKKBNa, 2012).

Pengetahuan remaja tentang kesehatan reproduksi menurut SDKI (2012) masih rendah. Remaja yang mengetahui bahwa perempuan bisa hamil walaupun hanya satu kali berhubungan seksual hanya 35\% pada remaja perempuan dan $31,2 \%$ pada remaja laki-laki usia 15-19 tahun. Sedangkan hanya $9,9 \%$ remaja perempuan dan $10,6 \%$ remaja laki-laki yang memiliki pengetahuan komprehensif mengenai HIV/AIDS.

Pada tahun 2011, sekitar 2,5 juta penduduk dunia meninggal karena minumminuman keras. Dari angka tersebut, sebesar 9\% kematian terjadi pada usia 15-29 tahun (WHO, 2015). Penggunaan alkohol pada remaja di Indonesia cukup tinggi, yaitu 3,5\% pada wanita dan $30,2 \%$ pada laki-laki usia 15-19 tahun. Sedangkan penggunaan alkohol di usia 20-24 tahun lebih tinggi, yaitu 7,1\% pada wanita dan 52,9\% pada laki-laki (SDKI, 2012). Penggunaan rokok pada remaja perempuan usia 15-19 tahun sebanyak 8,9\% dan $74,4 \%$ pada remaja laki-laki. Sedangkan penggunaan rokok pada remaja usia 20-24 tahun lebih tinggi, yaitu $14,0 \%$ pada perempuan dan $89,2 \%$ pada laki-laki (SDKI, 2012).

Pendidikan kecakapan hidup bagi remaja sangat penting untuk mendukung perkembangan individu agar menjadi orang dewasa yang bertanggungjawab. Untuk menjalani hidup yang teratur, individu memerlukan keterampilan-keterampilan yang dibutuhkan masyarakat untuk melakukan sesuatu secara teratur (Hadjam, 2010). Rao (2008) dalam penelitianya menyebutkan bahwa untuk menjalani kehidupan yang sehat, bertanggungjawab, memenuhi dan melindungi diri dari masalah kesehatan reproduksi, orang-orang muda perlu memahami diri mereka sendiri, memahami orang-orang yang berhubungan dengan mereka serta memerlukan informasi tentang perubahan fisik, psikologis dan sosial yang perlu ditanamkan sejak masa kanak-kanak dan remaja.

Menanggapi permasalahan remaja yang begitu kompleks dewasa ini, pemerintah berupaya dengan mencanangkan berbagai program terkait kesehatan reproduksi remaja. Program-program tersebut antara lain Kelompok Siswa Peduli AIDS dan Narkoba (KSPAN), Pelayanan Kesehatan Peduli Remaja (PKPR) dan Pusat Informasi dan Konseling Remaja (PIK-R). Program Pusat Informasi dan Konseling Remaja (PIK-R) merupakan salah satu wadah yang dikembangkan dari program Generasi 
Berencana (GenRe). Tujuannya adalah untuk memberikan pelayanan informasi dan konseling kesehatan reproduksi, pendewasaan usia perkawinan, delapan fungsi keluarga, Tiga Risiko Kesehatan Reproduksi yang Dihadapi Remaja (TRIAD KRR), kecakapan hidup, gender serta kemampuan advokasi dan KIE. Peran PIK-R bagi remaja sangatlah penting. Salah satunya adalah memudahkan remaja mengakses informasi dan layanan konseling tentang kehidupan berkeluarga bagi siswa (BKKBNc, 2012). Hal ini sesuai dengan tujuan program PIK-R yaitu Tegar Remaja untuk mencapai keluarga kecil bahagia sejahtera. Tegar remaja didefinisikan sebagai remaja yang memiliki perilaku hidup sehat, menghindari risiko TRIAD KRR, pendewasaan usia perkawinan, memiliki rencana kehidupan berkeluarga dalam mewujudkan keluarga kecil bahagia sejahtera. Selain itu, remaja diharapkan dapat menjadi sumber informasi tentang kesehatan reproduksi bagi teman sebayanya (BKKBNa, 2012).

Kegiatan-kegiatan yang dilakukan dalam Program PIK-R dalam rangka mencapai tujuan program antara lain penyuluhan dan pembinaan, konseling, penyelenggaraan seminar-seminar terkait kesehatan reproduksi, serta dialog interaktif di radio atau TV. Kegiatan keterlibatan dalam aktifitas sosial dilakukan dengan kampanye Perilaku Hidup Sehat Berwawasan Kependudukan (PHBK), kebersihan lingkungan, pelayanan kesehatan serta aktifitas sosial lainnya. Untuk menarik minat remaja agar datang dan memanfaatkan layanan PIK-R, dilakukan kegiatan-kegiatan seperti jambore remaja, studi banding, kegiatan kesenian, lomba-lomba yang berkaitan, outbond, bedah buku, bedah film, kegiatan ekonomi produktif dan olahraga. Materi-materi terkait kesehatan reproduksi juga dikembangkan sesuai dengan kebutuhan, misalnya pengembangan materi mengenai gender. Agar remaja memiliki kemampuan advokasi dan KIE, program PIK-R melatih pendidik dan konselor sebaya untuk memberikan informasi kepada teman sebayanya. Seiring dengan perkembangan IT, Program PIK-R mengembangkan teknologi konsultasi dan konseling melalui akses terhadap jaringan internet, jejaring sosial (facebook, twiter, instagram, whatshap), serta SMS konseling (BKKBNa, 2012).

Menilai efektifitas suatu program merupakan hal yang penting untuk menentukan apakah program tersebut dilaksanakan sebagaimana yang dimaksud serta mengidentifikasi hambatan pelaksanaan program dan bagaimana mengatasinya. Informasi ini sangat penting untuk menentukan alasan keberhasilan atau kegagalan suatu program (Robinson dan Rogstad, 2002). Pengetahuan mengenai efektifitas program sangat penting bagi pemegang program kesehatan sehingga dapat ditentukan apakah program tersebut perlu dilanjutkan atau tidak. Hal ini dapat dinilai dengan melakukan evaluasi program untuk mengetahui apakah pencapaiannya telah sesuai dengan tujuan program. Sosialisasi dan ekstrakurikuler PIK-R telah dilaksanakan di SMA-SMA di Kabupaten Tabanan.

Berdasarkan uraian latar belakang di atas, terlihat bahwa peran PIK-R sangatlah besar bagi remaja. Salah satunya adalah mampu menciptakan remaja yang memiliki kecakapan hidup yang baik terutama yang terkait dengan kesehatan reproduksi. Oleh karena itu, peneliti ingin mengetahui gambaran kecakapan hidup remaja yang mengikuti Program PIK-R di SMA Negeri di Kabupaten Tabanan Tahun 2017.

\section{Metode Penelitian}

Rancangan penelitian yang digunakan adalah cross sectional analitik dengan cara survey. Pengambilan data dilakukan di tiga SMA Negeri di Kabupaten Tabanan, yaitu SMA Negeri 1 Marga, SMA Negeri 1 Kerambitan dan SMA Negeri 1 Kediri pada tanggal 13 sampai dengan 18 Maret 2017. Alasan pemilihan SMA ini adalah karena Program PIK-R telah dilaksanakan dengan baik di SMA ini. Sumber data dalam penelitian ini adalah survei langsung kepada subjek penelitian. Data mengenai jumlah SMA yang melaksanakan program PIK-R 
diperoleh dari laporan pemegang program PIK-R dari BKKBN. Data mengenai kecakapan hidup terkait kesehatan reproduksi remaja diperoleh dari jawaban kuesioner yang telah disiapkan oleh peneliti.

Populasi target dalam penelitian ini adalah siswa SMA di Provinsi Bali. Sedangkan populasi terjangkau adalah siswa SMA di Kabupaten Tabanan. Sampel dalam penelitian ini adalah siswa SMA yang mengikuti Program PIK-R di Kabupaten Tabanan yang berjumlah 150 orang. Teknik sampling yang digunakan dalam penelitian ini adalah purposive sampling. Instrument yang digunakan berupa kuesioner yag terkait dengan kecakapan hidup tentang kesehatan reproduksi remaja.

Analisis data univariat dilakukan secara deskriptif dengan tabel distribusi frekuensi yang meliputi karakteristik responden dan kecakapan hidup terkait kesehatan reproduksi remaja. Variabel kecakapan hidup terkait kesehatan reproduksi diukur dengan 13 butir pernyataan negatif dan positif dengan empat pilihan jawaban. Untuk pernyataan negatif, jawaban sangat tidak setuju diberi skor 4 , tidak setuju diberi skor 3, setuju diberi skor 2 dan sangat setuju diberi skor 1 . Sedangkan untuk pernyataan positif, jawaban sangat tidak setuju diberi skor 1, tidak setuju diberi skor 2, setuju diberi skor 3 dan sangat setuju diberi skor 4. Jika siswa memperoleh skor 1 atau 2 pada setiap item pertanyaan, maka dikategorikan ke dalam kecakapan hidup kurang, sedangkan skor 3 atau 4 dikategorikan ke kecakapan hidup baik. Skor tertinggi adalah 52 dan skor terendah adalah 13. Kemudian setiap item pertanyaan dari variabel kecakapan hidup dijabarkan untuk melihat distribusi jawaban benar responden pada setiap item pertanyaan. Penyajian hasil analisis menggunakan tabel distribusi frekuensi dengan menampilkan nilai frekuensi relatif dan persentase (\%). Setelah itu variabel kecakapan hidup akan dikelompokkan ke dalam dua kategori. Siswa diyatakan memiliki kecakapan hidup yang baik apabila skor yang diperoleh $\geq 39$ dan dinyatakan memiliki kecakapan hidup yang kurang jika skor yang diperoleh $<39$.

\section{Hasil dan Pembahasan}

Kabupaten Tabanan merupakan salah satu Kabupaten di Provinsi Bali dengan wilayah geografis yang cukup luas. Jumlah penduduk cukup besar yaitu sekitar 435.900 jiwa. Dilihat dari komposisi penduduk Kabupaten Tabanan, jumlah penduduk usia sekolah (10-19 tahun) sekitar 60.300 jiwa (BPS, 2015). Dengan jumlah penduduk usia sekolah yang cukup banyak, wilayah Kabupaten Tabanan memiliki 9 SMA negeri, 6 SMA swasta, 4 Madrasah Alawiyah, 3 SMK negeri dan 11 SMK swasta. Untuk menanggulangi permasalahan kesehatan reproduksi remaja, pemerintah telah mencanangkan program kesehatan reproduksi berbasis sekolah di Kabupaten Tabanan.

Penelitian ini dilakukan di tiga SMA Negeri di Kabupaten Tabanan, yaitu SMA Negeri 1 Kerambitan, SMA Negeri 1 Marga dan SMA Negeri 1 Kediri. Jumlah responden adalah 150 siswa SMA yang mengikuti ekstrakurikuler PIK-R, dimana 48 siswa berasal dari SMA Negeri 1 Kerambitan, 50 siswa berasal dari SMA Negeri 1 Marga dan 52 siswa berasal dari SMA Negeri 1 Kediri. Karakteristik subjek penelitian dapat dilihat pada Tabel 1 di bawah ini. 
Tabel 1 Karakteristik Subjek Penelitian (n=150 orang)

\begin{tabular}{lccc}
\hline Karakteristik & n $(\%)$ & Mean & SD \\
\hline Umur (tahun) & & 16,25 & 0,67 \\
15 & $17(11,33)$ & \\
16 & $80(53,33)$ & \\
17 & $51(34,00)$ & \\
18 & $2(1,33)$ & \\
Jenis Kelamin & $56(37,33)$ & \\
Laki-laki & $94(62,67)$ & \\
Perempuan & $150(100,00)$ & \\
\hline Jumlah & \\
\hline
\end{tabular}

Deskripsi Kecakapan Hidup Terkait Kesehatan Reproduksi Remaja

Kecakapan hidup dinilai dengan kuesioner yang terdiri dari 13 pertanyaan dengan 4 pilihan jawaban. Jika siswa memperoleh skor 1 atau 2 pada setiap item pertanyaan, maka dikategorikan ke dalam kecakapan hidup kurang, sedangkan skor 3 atau 4 dikategorikan ke dalam kecakapan hidup baik. Skor maksimal yang dapat diperoleh siswa adalah 52 dan skor minimal adalah 13. Tabel 2 dibawah ini mendeskripsikan setiap item pertanyaan yang terkait dengan kecakapan hidup mengenai kesehatan reproduksi remaja pada siswa SMA di Kabupaten Tabanan tahun 2017.

Tabel 2 Deskripsi Kecakapan Hidup terkait Kesehatan Reproduksi pada Siswa SMA di Kabupaten Tabanan Tahun 2017 ( $\mathrm{n}=150$ orang)

\begin{tabular}{|c|c|c|c|c|c|c|}
\hline \multirow{2}{*}{$\begin{array}{l}\text { Komponen Penilaian Kecakapan } \\
\text { Hidup terkait Kesehatan Reproduksi }\end{array}$} & \multicolumn{3}{|c|}{ Kurang n(\%) } & \multicolumn{3}{|c|}{ Cakap n (\%) } \\
\hline & $\mathrm{L}(\%)$ & $\mathbf{P}(\%)$ & Jml (\%) & $\mathrm{L}(\%)$ & $\mathbf{P}(\%)$ & $\begin{array}{l}\text { Jml } \\
(\%)\end{array}$ \\
\hline $\begin{array}{l}\text { Hak untuk mendapat informasi yang } \\
\text { benar serta pelayanan kesehatan } \\
\text { reproduksi yang baik di sekolah }\end{array}$ & $\begin{array}{c}0 \\
(0,00)\end{array}$ & $\begin{array}{c}1 \\
(1,06)\end{array}$ & $\begin{array}{c}1 \\
(0,67)\end{array}$ & $\begin{array}{c}56 \\
(100,00)\end{array}$ & $\begin{array}{c}93 \\
(98,94)\end{array}$ & $\begin{array}{c}149 \\
(99,33)\end{array}$ \\
\hline $\begin{array}{l}\text { Melalui masa pubertas dengan baik dan } \\
\text { sehat dengan cara menghindari perilaku } \\
\text { berisiko }\end{array}$ & $\begin{array}{c}3 \\
(5,36)\end{array}$ & $\begin{array}{c}0 \\
(0,00)\end{array}$ & $\begin{array}{c}3 \\
(2,00)\end{array}$ & $\begin{array}{c}53 \\
(94,64)\end{array}$ & $\begin{array}{c}94 \\
(100,00)\end{array}$ & $\begin{array}{c}147 \\
(98,00)\end{array}$ \\
\hline $\begin{array}{l}\text { Meningkatkan pengetahuan terkait } \\
\text { kesehatan reproduksi dengan cara } \\
\text { mengikuti seminar, membaca } \\
\text { buku/majalah dan mencari informasi di } \\
\text { internet }\end{array}$ & $\begin{array}{c}5 \\
(8,93)\end{array}$ & $\begin{array}{c}0 \\
(0,00)\end{array}$ & $\begin{array}{c}5 \\
(3,33)\end{array}$ & $\begin{array}{c}51 \\
(91,07)\end{array}$ & $\begin{array}{c}94 \\
(100,00)\end{array}$ & $\begin{array}{c}145 \\
(96,67)\end{array}$ \\
\hline $\begin{array}{l}\text { Tidak melakukan hubungan seks dengan } \\
\text { pacar walaupun atas dasar suka sama } \\
\text { suka dan sebagai bukti kasih dan sayang }\end{array}$ & $\begin{array}{c}26 \\
(46,43\end{array}$ & $\begin{array}{c}1 \\
(1,06)\end{array}$ & $\begin{array}{c}27 \\
(18,00\end{array}$ & $\begin{array}{c}30 \\
(53,57\end{array}$ & $\begin{array}{c}93 \\
(98,94)\end{array}$ & $\begin{array}{c}123 \\
(82,00)\end{array}$ \\
\hline $\begin{array}{l}\text { Mampu menyarankan teman untuk } \\
\text { berobat ke tenaga kesehatan apabila } \\
\text { mengalami masalah kesehatan } \\
\text { reproduksi }\end{array}$ & $\begin{array}{c}2 \\
(3,57)\end{array}$ & $\begin{array}{c}1 \\
(1,06)\end{array}$ & $\begin{array}{c}3 \\
(2,00)\end{array}$ & $\begin{array}{c}54 \\
(96,43)\end{array}$ & $\begin{array}{c}93 \\
(98,94)\end{array}$ & $\begin{array}{c}147 \\
(98,00)\end{array}$ \\
\hline $\begin{array}{l}\text { Tidak merasa malu menceritakan kepada } \\
\text { orang lain ketika mengalami } \\
\text { permasalahan kesehatan reproduksi }\end{array}$ & $\begin{array}{c}32 \\
(57,14)\end{array}$ & $\begin{array}{c}39 \\
(41,49)\end{array}$ & $\begin{array}{c}71 \\
(47,33)\end{array}$ & $\begin{array}{c}24 \\
(42,86)\end{array}$ & $\begin{array}{c}55 \\
(58,51)\end{array}$ & $\begin{array}{c}79 \\
(52,67)\end{array}$ \\
\hline $\begin{array}{l}\text { Memeriksakan diri ke tenaga kesehatan } \\
\text { ketika mengalami permasalahan } \\
\text { kesehatan reproduksi }\end{array}$ & $\begin{array}{c}3 \\
(5,36)\end{array}$ & $\begin{array}{c}0 \\
(0,00)\end{array}$ & $\begin{array}{c}3 \\
(2,00)\end{array}$ & $\begin{array}{c}53 \\
(94,64)\end{array}$ & $\begin{array}{c}94 \\
(100,00)\end{array}$ & $\begin{array}{c}147 \\
(98,00)\end{array}$ \\
\hline $\begin{array}{l}\text { Tidak segan menceritakan masalah } \\
\text { kesehatan reproduksi dengan teman } \\
\text { sebaya }\end{array}$ & $\begin{array}{c}30 \\
(53,57)\end{array}$ & $\begin{array}{c}55 \\
(58,51)\end{array}$ & $\begin{array}{c}85 \\
(56,67)\end{array}$ & $\begin{array}{c}26 \\
(46,43)\end{array}$ & $\begin{array}{c}39 \\
(41,49)\end{array}$ & $\begin{array}{c}65 \\
(43,33)\end{array}$ \\
\hline
\end{tabular}


Berdasarkan Tabel 2 di atas dapat dilihat bahwa poin penilaian kecakapan hidup yang terendah yaitu menceritakan permasalahan kesehatan reproduksi dengan teman sebaya. Sebanyak 30 orang $(53,57 \%)$ responden lakilaki dan 55 orang $(58,51 \%)$ responden perempuan merasa tidak nyaman menceritakan masalah kesehatan dengan teman sebaya. Demikianpula pada poin menceritakan kepada orang lain apabila mengalami masalah terkait kesehatan reproduksi. Sebanyak 32 orang $(57,14 \%)$ reponden laki-laki dan 39 orang $(41,49 \%)$ reponden perempuan merasa malu menceritakan kepada orang lain apabila mengalami masalah terkait kesehatan reproduksi.

Kecakapan hidup secara keseluruhan dinilai dengan perolehan total skor. Siswa diyatakan memiliki kecakapan hidup yang baik apabila skor yang diperoleh $\geq 39$ dan dinyatakan memiliki kecakapan hidup yang kurang jika skor yang diperoleh <39. Tabel 3 di bawah ini menunjukkan distribusi frekuensi kecakapan hidup terkait kesehatan reproduksi pada siswa SMA di Kabupaten Tabanan tahun 2017.

Tabel 3 Kecakapan Hidup terkait Kesehatan Reproduksi pada Siswa SMA di Kabupaten Tabanan Tahun $2017(n=150)$

\begin{tabular}{lcc}
\hline Kecakapan Hidup & $\mathbf{n}$ & $\mathbf{\%}$ \\
\hline Baik & 116 & 77,33 \\
Kurang & 34 & 22,67 \\
\hline Jumlah & $\mathbf{1 5 0}$ & $\mathbf{1 0 0 , 0 0}$ \\
\hline
\end{tabular}

Berdasarkan Tabel 3 di atas dapat dilihat bahwa sebagian besar siswa SMA di Kabupaten Tabanan memiliki kecakapan hidup yang baik terkait kesehatan reproduksi, yaitu sebanyak 116 orang $(77,33 \%)$. Skor minimal yang diperoleh siswa adalah 31 dan skor maksimal adalah 50.

Berdasarkan hasil penelitian dapat dilihat bahwa sebagian besar siswa SMA di Kabupaten Tabanan memiliki kecakapan hidup yang baik terkait kesehatan reproduksi, yaitu sebanyak 77,33\%. Poin penilaian kecakapan hidup yang terendah yaitu menceritakan permasalahan kesehatan reproduksi dengan teman sebaya. Sebanyak 30 orang $(53,57 \%)$ responden laki-laki dan 55 orang $(58,51 \%)$ responden perempuan merasa tidak nyaman menceritakan masalah kesehatan dengan teman sebaya. Demikianpula pada poin menceritakan kepada orang lain apabila mengalami masalah terkait kesehatan reproduksi. Sebanyak 32 orang $(57,14 \%)$ reponden lakilaki dan 39 orang $(41,49 \%)$ reponden perempuan merasa malu menceritakan kepada orang lain apabila mengalami masalah terkait kesehatan reproduksi.

Pendidikan kecakapan hidup bagi remaja sangat penting untuk mendukung perkembangan individu agar menjadi orang dewasa yang bertanggungjawab. Untuk menjalani hidup yang teratur, individu memerlukan keterampilan-keterampilan yang dibutuhkan masyarakat untuk melakukan sesuatu secara teratur (Hadjam, 2010).

Program PIK-R merupakan salah satu wadah yang dikembangkan melalui program Generasi Berencana (GenRe) yang dikelola dari, oleh dan untuk remaja. Fungsinya adalah menyediakan layanan informasi dan konseling terkait kesehatan reproduksi, pendewasaan usia perkawinan, delapan fungsi keluarga, TRIAD KRR, kecakapan hidup, gender serta keterampilan advokasi dan KIE. Untuk memudahkan remaja dalam mendapatkan informasi dan pelayanan konseling yang benar terkait kehidupan berkeluarga dan kesehatan reproduksi, maka peran PIK-R sangatlah penting.

Menurut penelitian yang dilakukan oleh Pakasi (2013), pendidikan seksualitas dan kesehatan reproduksi di sekolah selama ini belum komprehensif dan sesuai dengan realitas. Perilaku seks dan risiko seksual yang dihadapi oleh remaja berimplikasi pada pengetahuan siswa yang masih terbatas. Hal ini dikarenakan pendidikan kesehatan reproduksi di sekolah terbatas pada aspek kesehatan reproduksi dan seksual remaja 
tentang fenomena biologis. Agar lebih efektif, pendidikan seksualitas dan kesehatan reproduksi perlu mengkonstruksikan seksualitas remaja secara positif sebagai makhluk seksual (sexual being) yang memiliki hak kesehatan reproduksi dan bertanggungjawab terhadap kesehatan seksual dan reproduksinya.

Penelitian lain yang dilakukan oleh James (2006) tentang dampak program keterampilan hidup terkait HIV/AIDS pada siswa sekolah menengah menunjukkan bahwa siswa yang mendapatkan intervensi penuh memiliki persepsi yang positif tentang perilaku seksual dan hubungan seksual dibandingkan dengan kelompok kontrol. Demikian pula mengenai hubungan seks bebas, lebih rendah pada kelompok intervensi, serta lebih banyak menggunakan kondom jika dibandingkan dengan kelompok kontrol.

Rao (2008) dalam penelitianya menyebutkan bahwa untuk menjalani kehidupan yang sehat, bertanggungjawab, memenuhi dan melindungi diri dari masalah kesehatan reproduksi, orang-orang muda perlu memahami diri mereka sendiri, memahami orang-orang yang berhubungan dengan mereka serta memerlukan informasi tentang perubahan fisik, psikologis dan sosial yang perlu ditanamkan sejak masa kanakkanak dan remaja.

Berdasarkan penelitian yang dilakukan oleh Putriani (2010) yang dilakukan di SMA Negeri 1 Mojogedang, menyatakan bahwa seseorang yang dianggap dekat/penting memberikan banyak pengaruh terhadap pengetahuan terkait kesehatan reproduksi. Hal ini tidak sejalan dengan hasil penelitian, dimana sebagian siswa merasa malu untuk menceritakan masalah kesehatan reproduksi kepada teman sebaya dan orang lain. Nilainilai yang ditanamkan orang tua juga memberikan pengaruh yang besar terhadap kecakapan hidup remaja terkait kesehatan reproduksi. Pendidikan seks yang terbaik adalah yang diberikan orang tua sendiri sejak dini. Orang tua hendaknya menanamkan sejak dini agar remaja tidak merasa tabu untuk membicarakan masalah seksual dan kesehatan reproduksi kepada orang lain sehingga mendapatkan solusi yang terbaik. Dampak yang ditimbulkan apabila siswa masih merasa malu menceritakan permasalahan seksual dan kesehatan reproduksi adalah siswa akan memendam sendiri masalah-masalah yang mereka hadapi, sehingga tidak menemukan solusi bagi permasalahan yang dihadapinya. Selain itu, apabila siswa masih merasa tabu untuk menceritakan permasalahan seksual dan kesehatan reproduksi, maka siswa tidak akan mau mengakses layanan kesehatan reproduksi yang telah disediakan.

\section{Simpulan}

Kecakapan hidup terkait kesehatan reproduksi pada siswa SMA di Kabupaten Tabanan yang mengikuti Program PIK-R tahun 2017 sebagian besar dalam kategori baik (77,33\%). Terlihat bahwa Program PIK$\mathrm{R}$ memberikan dampak yang positif bagi kecakapan hidup siswa yang mengikuti program tersebut. Diharapkan kepada pemerintah, sekolah dan pemegang Program Kesehatan Reproduksi Remaja agar meningkatkan kualitas program sehingga animo mahasiswa untuk mengikuti program PIK-R tersebut meningkat, serta mencetak lebih banyak remaja yang bertanggungjawab dan memiliki kecakapan hidup yang baik terhadap kesehatan reproduksinya.

\section{Referensi}

BKKBN, 2007. Materi TRIAD KRR. [cited Okt 2016. 14] Available at: https://www.docdroid.net/vhwp/mate ri-triad-krr.pdf.html

BKKBN, 2012a. Pedoman Pengelolaan Bina Keluarga Remaja (BKR). [cited Okt $2016 . \quad 14]$ Available at: http://www.bkkbn.go.id

BKKBN, 2012b.Pedoman Pengelolaan Pusat Informasi dan Konseling Remaja dan Mahasiswa (PIK R/M). [cited Sept 2016. 13] Available at: http://binsos.jatengprov.go.id/file\%2 0pdf/pikrm.pdf

BKKBN, 2012c. Kajian Pernikahan Dini pada Beberapa Provinsi di Indonesia: 
Dampak Overpopulation, Akar Masalah dan Peran Kelembagaan di Daerah. [cited Okt. 2016. 4]

Gunarsa, SD. dan Gunarsa, YSD. 2008. Psikologi Praktis: Anak, Remaja dan Keluarga. Jakarta: Gunung Mulia

Hadjam, NR. Prof. Dr. M. SU. 2010. Peran Kepribadian dalam Peningkatan Kecakapan Hidup. Makalah Fakultas Psikologi UGM. [cited Okt 2016. 17] Available from: http://psikologi.ugm.ac.id/uploads/re sources

Infodatin. 2015. Situasi Kesehatan Reproduksi Remaja. Kementerian Kesehatan RI. [cited Sept. 2016. 24] Available at: http://www.depkes.go.id

James, S. Et al. 2006.The Impact of an HIV and AIDS Life Skills Program on Secondary School Student in Kwazulu - Natal, South Africa.Journal AIDS Education and Prevention, 18 (4), 281 - 294, 2006. [cited Nov 2016. 11]. Available from:

http://search.proquest.com/openview

Kemenkes RI, 2013. Riset Kesehatan Dasar. [cited Augst 2016. 29] Available at: http://www.depkes.go.id/resources/d ownload/general

Kemenkes RI, 2015. Profil Kesehatan Indonesia. [cited Sept. 2016. 24] Available at: http://www.depkes.go.id

Kisara, Bali. 2016. Gambaran Pengetahuan, Sikap dan Perilaku tentang Kesehatan Reproduksi dan Seksual pada Remaja di Kota Denpasar. [Cited May 2017. 5]. Available at: http://www.kisara.or.id

Kitab Undang Undang Hukum Perdata. [cited Des. 2016. 28]. Available at: http://hukum.unsrat.ac.id/uu/kolonial _kuh_perdata.pdf

Lestary, H dan Sugiharti. 2007. Perilaku Berisiko Remaja di Indonesia Menurut Survey Kesehatan Reproduksi Remaja Indonesia (SKRRI) Tahun 2007. Jurnal
Kesehatan Reproduksi Vol. 1 No. 3. Agustus 2011 : 136 - 144. [cited Nov 2016. 11]. Available from: http://download.portalgaruda.org/arti cle

Pakasi, D.T dan Kartikawati, R. 2013. Antara Kebutuhan dan Tabu : Pendidikan Seksualitas dan Kesehatan Reproduksi bagi Remaja di SMA. (Makara Seri Kesehatan, 2013, 17(2) : 79-87DOI: 10.7454/msk.v17i2.xxxx). [cited Okt 2016. 20]. Available from: journal.ui.ac.id/index.php/health/artic le

Putriani, N. 2010. Faktor-Faktor yang Mempengaruhi Pengetahuan Remaja tentang Kesehatan Reproduksi di SMA Negeri 1 Mojogedang. Naskah Publikasi. [cited May 2017. 1]. Available from: https://core.ac.uk/download/pdf/1171 0959.pdf

Rao, RSP. 2008. Effectiveness of reproductive health education among rural adolescent girls: A school based intervention study in Udupi Taluk, Karnataka. Indian Journal of Medical Sciences 62.11 (Nov 2008) : 439-43. [cited Nov. 2016.11$].$ Available from: http://search.proquest.com

Robinson, AJ dan Rogstad, K, 2002. Adolescence : a Time of Risk Taking. Article. [cited Nov. 2016. 26]. Available from: http://sti.bmj.com/content

Undang Undang Republik Indonesia Nomor 1 Tahun 1974 tentang Perkawinan. [cited Des. 2016. 28]. Available at: www.hukumonline.com

Undang Undang Republik Indonesia Nomor 35 Tahun $2014 \quad$ Tentang Perlindungan Anak. [cited Des. 2016. 28]. Available at: www.hukumonline.com

Undang Undang Republik Indonesia Nomor 36 Tahun 2009 tentang Kesehatan. [cited Nov. 2016. 11]. Available at: http://sireka.pom.go.id/requirement 
UNDESA, 2010. Monthly Briefing World Economic Situation an Prospects. [cited Sept. 2016. 24] Available at: http://www.un.org

World Health Organization (WHO), 2003. WHO Information Series on School Health : Family Life, Reproductife Health and Population Education. [cited Nov 2016. 28]. Available at: http://www.who.int/school

World Health Organization (WHO). World Health Statistic 2015. [cited Sept. 2016. 24] Available at: http://apps.who.int/iris/bitstream 